\title{
Forming process analysis of an AA6060 aluminum vessel
}

\author{
Gillo Giuliano, Costanzo Bellini, Luca Sorrentino, Sandro Turchetta \\ University of Cassino and Southern Lazio, Department of Civil and Mechanical Engineering, Italy \\ gillo.giuliano@unicas.it \\ costanzo.bellini@unicas.it, bttp:/ /orcid.org/0000-0003-4804-6588 \\ luca.sorrentino@unicas.it,bttp:/ / orcid.org/0000-0002-5278-7357 \\ sandro.turchetta@unicas.it,http://orcid.org/0000-0002-8365-8910
}

\begin{abstract}
This work analyses the results of a simple forming process of an AA6060 aluminum alloy sheet in order to validate the development of a simulation model based on the finite element method (FEM). This work represents the starting point of a broader study aimed at analyzing the sheet formability. The FEM based model and the use of both the flow stress curve and the formability limit curve (FLC) were validated through the simulation of a simple forming process that required use of a hemispherical punch. The detailed analysis of the machining process by using FEM allows significant time and cost savings, avoiding "trial-and-error" operations that are normally used in the setup phase of the production process.
\end{abstract}

KEYwORDS. AA6060 aluminum alloy; Forming process; Finite element method; Formability limit curve.

\section{OPEN@ACCESS}

Citation: Giuliano, G., Bellini, C., Sorrentino, L., Turchetta, S., Forming Process Analisys of an AA6060 Aluminium Vessel, Frattura ed Integrità Strutturale, 45 (2018) 164-172.

Received: 28.05.2018

Accepted: 15.06 .2018

Published: 01.07.2018

Copyright: (C) 2018 This is an open access article under the terms of the CC-BY 4.0, which permits unrestricted use, distribution, and reproduction in any medium, provided

the original author and source are credited.

\section{INTRODUCTION}

S heet metal forming is defined as a sheet metal process of transformation in the desired shape without fracture or excessive localized thinning. It represents one of the most important processing techniques of the automotive and aerospace industries.

Considerable efforts have been made over the years to develop more accurate theoretical models and methods to predict the feasibility of the forming process [1-3]. In such manner, it is possible to consider die modifications or to identify the appropriate process variables during the product production phase. Various commercial software based on the FEM are available for the analysis of the sheet metal forming process; however, to verify the FEM analysis results by means of experimental tests is very important; therefore, the metals forming is a matter of intense theoretical and experimental research.

The formability, that is the capacity of the sheet to undergo deformation without incurring the fracture, expresses an important characteristic to be investigated in the field of metal forming. The formability limit curve (FLC) is frequently used to evaluate the formability of the sheet metal. It illustrates the behaviour of the sheet metal, in terms of principal strains measured in the sheet plane, as a result of different strain paths. The FLC is represented by a graph of the principal 
strain measured at the beginning of the localized necking for all the possible values of the minor strain, as shown in Fig. 1. The comparison of the principal strains points location with the FLC allows to determine the defects onset in terms of necking (strain localizing) or fracture of the material. Finite element software uses FLC to examine the strains distribution in sheet metal parts. The FLC can be determined by experimental [4], theoretical [5-7] or hybrid methods [8] that combine experimental data with analytical or numerical approaches. An examination of different methods for determining FLC is presented in [9]. The theoretical methods are based on necking or material fracture criteria. Among the experimental methods, the most used is the Nakazima test for its simplicity. The test consists in making a hemispherical punch advance at a constant speed against a sheet bound between a die and a blank holder and allowing it to stretch until the necking or the fracture arises. This test is carried out on rectangular specimens with different widths so as to induce different strain states in the material, from the state of monoaxial stress to that of balanced stress. The maximum and minimum strains are detected by means of a reference grid drawn on the specimens before carrying out the test.

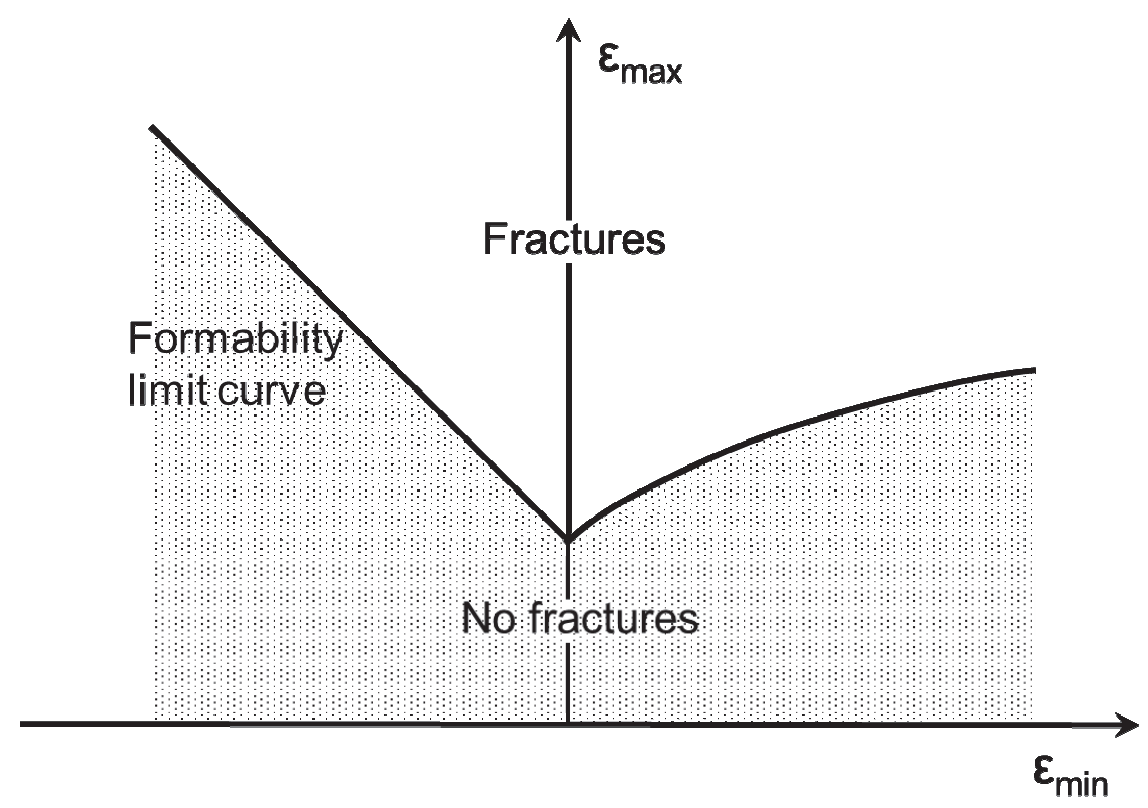

Figure 1: Typical FLC for sheet metal.

Usually, the FEM evaluation of the feasibility of forming operations is obtained by comparing the estimated strains with the FLC. In the absence of this comparison, the numerical simulation can continue even after reaching the sheet fracture conditions. For this reason, some FEM software packages allow implementing criteria for fracture or strain localization. In this work, in order to validate the adopted FEM model, the results of an AA 6060 aluminum sheet forming process were compared with those resulting from numerical analysis.

\section{EXPERIMENTAL ACTIVITY}

7 he studied material consisted in a $1 \mathrm{~mm}$ thick sheet, made of an aluminium-magnesium-silicon alloy known as AA 6060 and characterized by the following chemical weight composition: Al- $0.6 \% \mathrm{Si}-0.3 \% \mathrm{Fe}-0.1 \% \mathrm{Mn}-0.6 \% \mathrm{Mg}-$ $0.1 \% \mathrm{Cu}-0.15 \% \mathrm{Zn}-0.05 \% \mathrm{Cr}-0.1 \% \mathrm{Ti}$. It was a general use alloy and it was characterized by a high corrosion resistance.

In order to determine the material constitutive law, needed for describing the mechanical behavior of the material in the considered numerical model, tensile tests were carried out according to the relevant standard UNI EN 10002-1:2004. The tests were performed using a two-column universal electromechanical testing machine with a $100 \mathrm{kN}$ capacity. The specimen was characterized by a resistant section of $20 \mathrm{~mm}^{2}$ and a thickness equal to the sheet one. Fig. 2 shows the standard specimen and Fig. 3 the real stress-strain curve obtained from the tensile test. From the results of the tensile test it was possible to determine the material constants present in the constitutive equation expressed by the power law: 


$$
\sigma=K \varepsilon^{n}
$$

where $\sigma$ and $\varepsilon$ are the stress and the strain, respectively; while $\mathrm{K}$ and $\mathrm{n}$ are characteristic constants of the material.

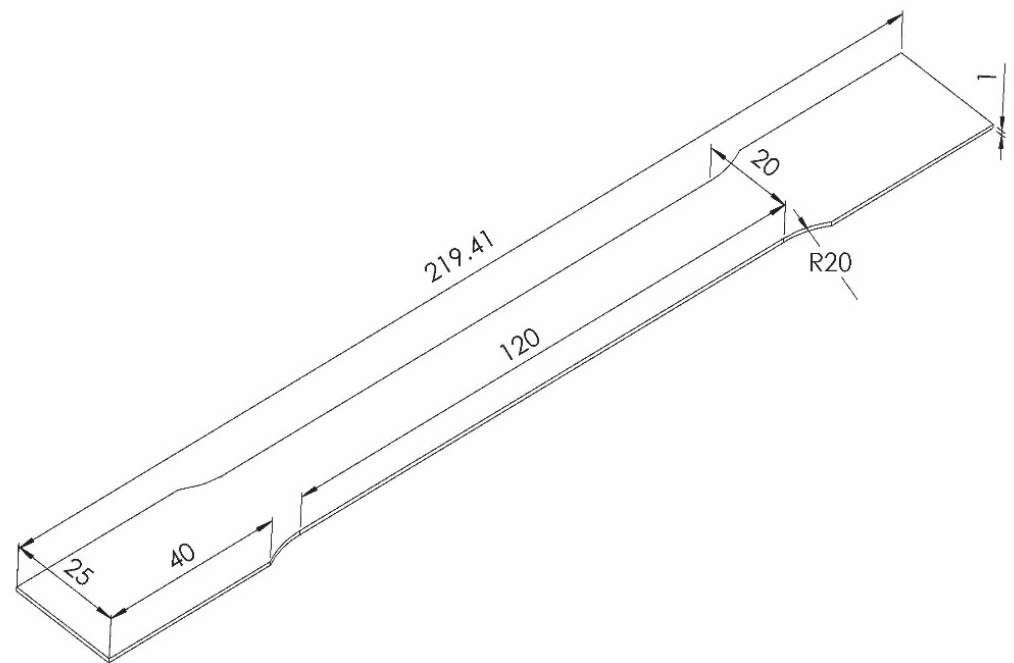

Figure 2: Geometrical characteristic of the tensile test specimen.

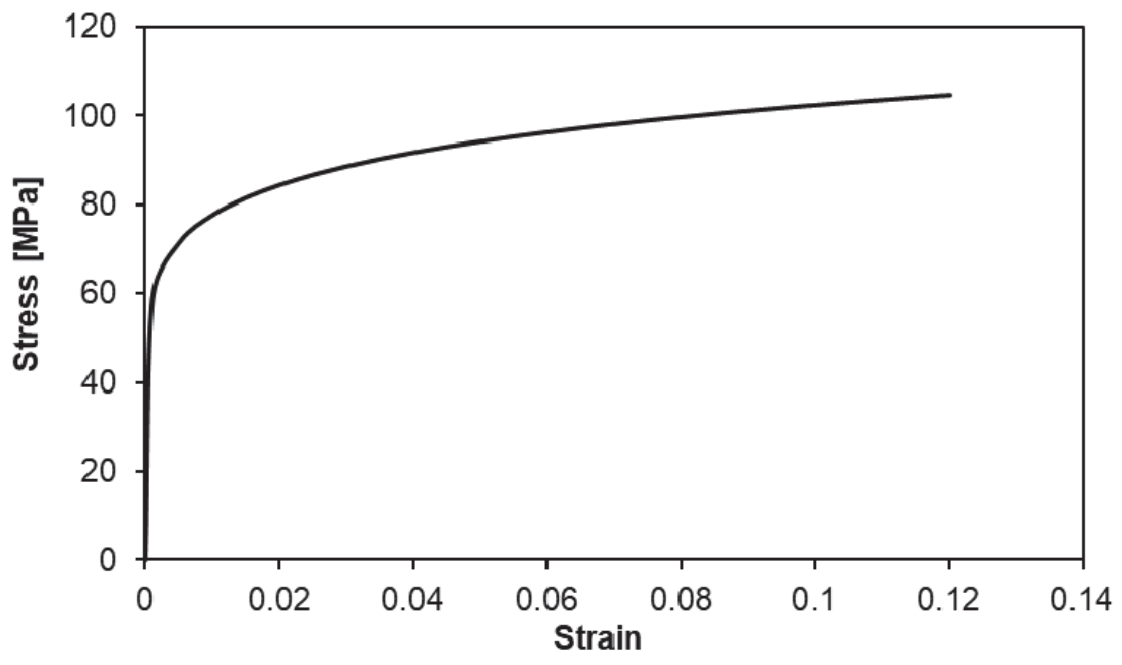

Figure 3: Real stress-strain curve definition obtained by tensile test (AA 6060 alloy).

In order to validate the FEM model, a forming test was carried out, schematically similar to the Nakazima test, but with larger geometric dimensions. In particular, the punch was characterized by a diameter of $60 \mathrm{~mm}$. To perform this test, special equipment designed and built at the Laboratory of Technology and Manufacturing System of the University of Cassino and Southern Lazio was used. Fig. 4 shows an operating schema of the equipment. The system regulating the vertical translation of the punch was based on a trapezoidal screw jack with an external female thread. The rotation of the screw, driven by an electric motor through a mechanical transmission system, dragged the external female thread, integral with the crosshead on which a punch coupled to a load cell was mounted, with an alternative straight upward or downward movement. The punch speed, equal to $3 \mathrm{~mm} / \mathrm{min}$, was selected by appropriately acting on the electric motor through an electronic apparatus (inverter). In the same schema of Fig. 4 it is also possible to observe the equipment capable of evaluating the force trend applied by the punch on the sheet during the test. It was constituted by a multimetre and a power supply, connected to the load cell placed under the punch. Fig. 5 shows the technical solution adopted for mounting the load cell on the movable crosshead. The sheet was clamped on the equipment by means of a steel plate, by tightening the apposite screws with a closing torque of $45 \mathrm{Nm}$ (Fig. 6). Further details on experimental equipment are 
given in [10-11]. The tests were conducted under different lubrication conditions of the punch-sheet system. Fig. 7 shows some steps for carrying out the test.

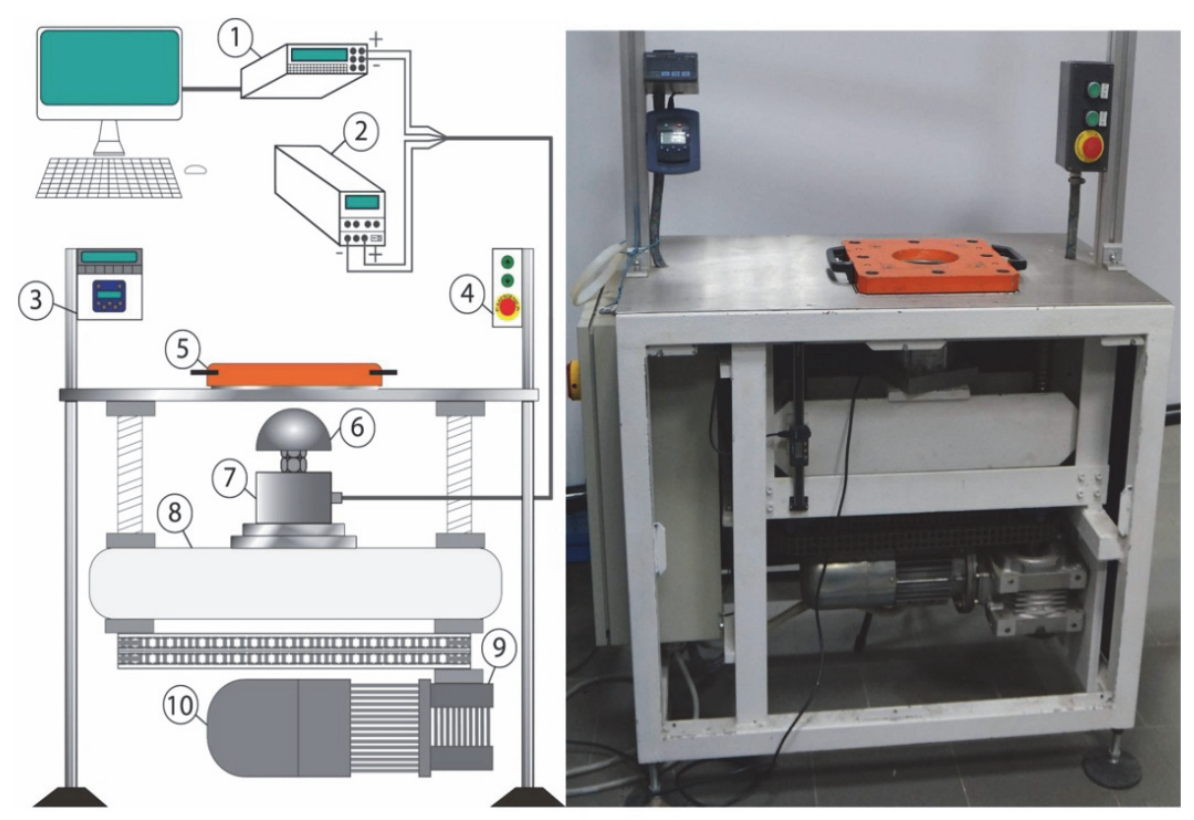

Figure 4: Equipment used for the forming test. The equipment scheme includes: 1) multimeter; 2) power supply; 3) interface for the test parameters management; 4) control panel for the punch translation; 5) die-drawbead component; 6) punch; 7) load cell; 8) crosshead; 9) translation system: rotating screw jack; 10) electric motor.

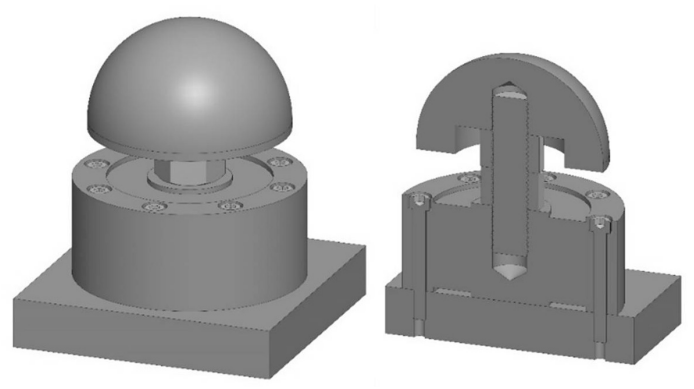

Figure 5: Technical solution for mounting the load cell on the crosshead.

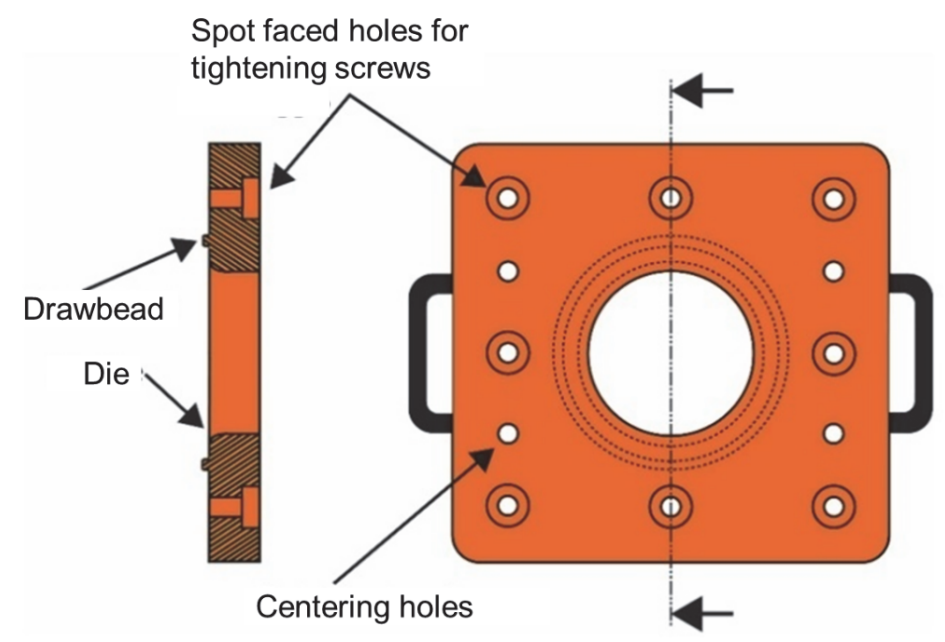

Figure 6: Die geometry. 

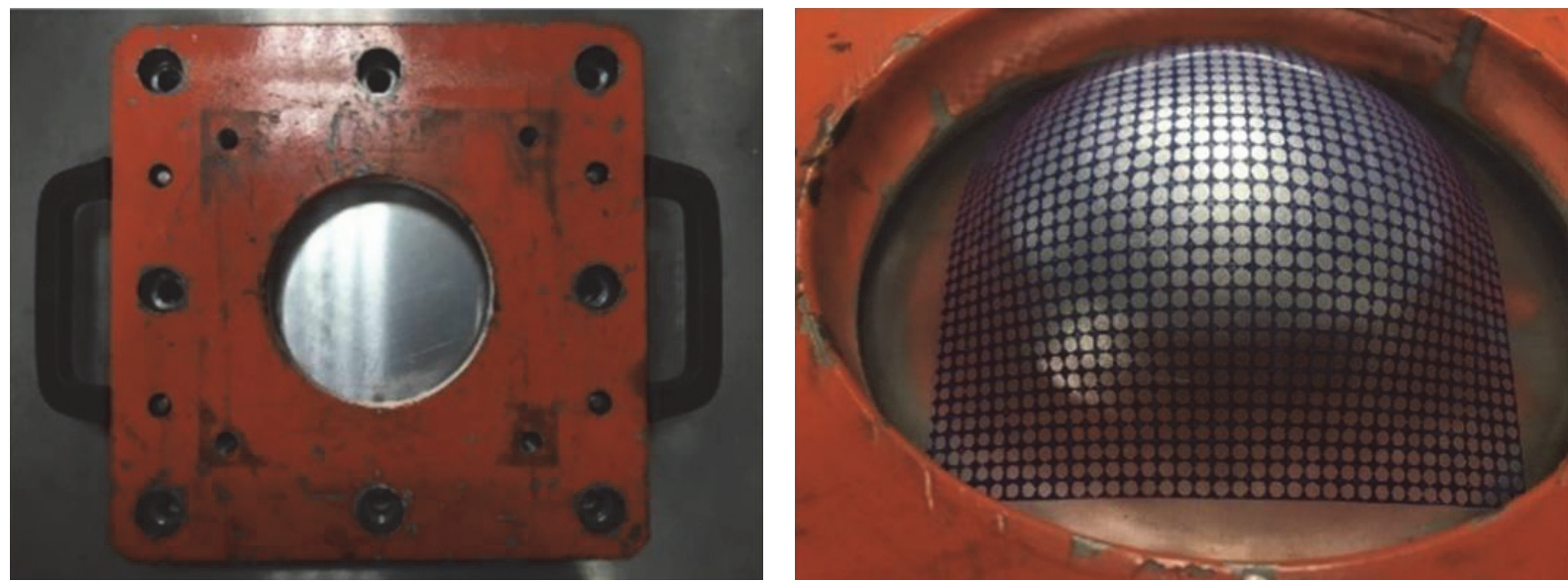

Figure 7: Some stages of the forming test.

\section{NUMERICAL ACTIVITY}

he FEM modeling was performed using the MSC.Marc 2005, a commercial calculation code. Modeling required a series of steps:

1. Drawing of the sheet and the used dies;

2. Subdivision of the deformable body into finite elements;

3. Definition of constraint conditions;

4. Definition of the material properties and the formability limit curve,

5. Definition of contact and friction conditions.

The previously described forming process was analyzed considering both a three-dimensional analysis (using shell elements) and a two-dimensional analysis (using axisymmetric elements). Fig. 8 shows the design of the used equipment (punch and die) as well as the discretized sheet metal in finite elements by both shell elements and axisymmetric elements.

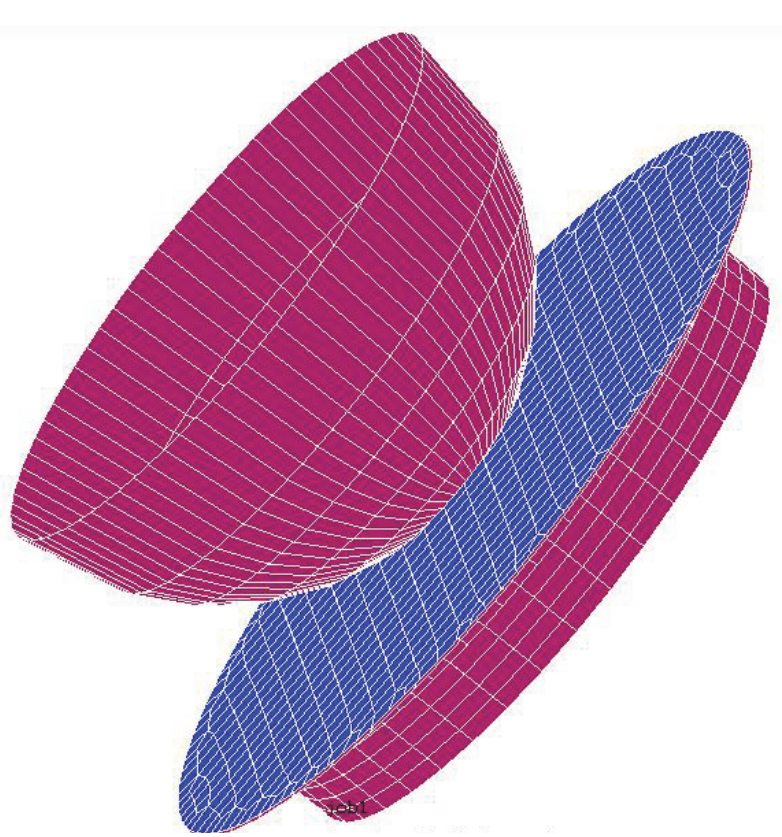

(a)

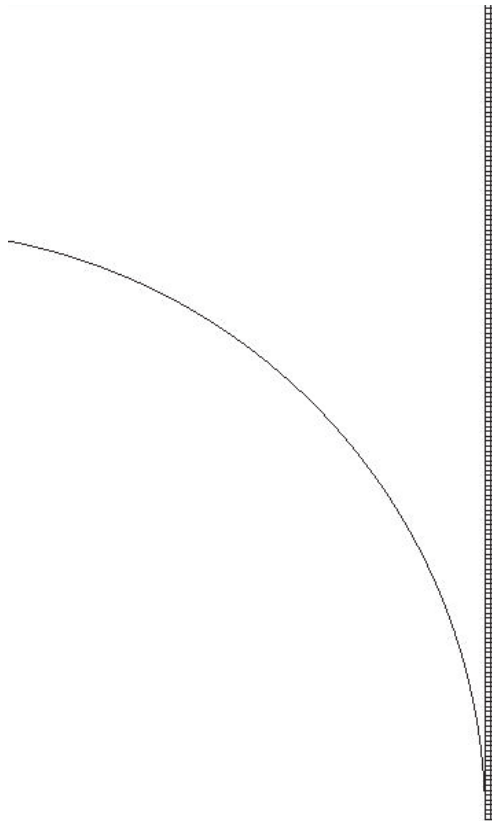

(b)

Figure 8: Drawing of the used equipment (punch and die) and of the sheet discretized with finite elements of the shell type (a) and the axisymmetric type (b). 
In the sheet peripheral area, the presence of a blank holder was simulated by imposing suitable constraint conditions. In particular, such constraint conditions prevented the sheet from sliding on the die. The contact conditions between bodies required the sheet to be defined as a deformable body while the die and the punch were defined as rigid bodies. In order to take account of the friction conditions between the punch and sheet and between the sheet and the die, the modified Coulomb friction model was chosen, whose relation between the tangential force $f_{t}$ and the normal force $f_{n}$ can be defined as:

$$
f_{t}=\mu f_{n}\left(\frac{2}{\pi}\right) \operatorname{arctg}\left(\frac{v_{r}}{\mathrm{R}_{s v}}\right)
$$

where $\mathrm{v}_{\mathrm{r}}$ is the relative sliding speed and $\mathrm{R}_{\mathrm{sv}}$ is the relative sliding speed at which the friction force tends to vanish. The coefficient of friction $\mu$ ranged from 0 to 0.2 .

The material behavior in the plastic field was described by the power law as Eqn. (1). In the adopted FEM code, to associate a formability limit curve to the deformable material was possible for shell elements, while to adopt a user-defined subroutine by introducing the most suitable FLC was necessary for axisymmetric elements. The introduction of the FLC allowed defining a formability limit parameter (FLP). The FLC, derived from Hill's local necking theory and Swift's diffuse necking theory, was dependent only on the material constant $\mathrm{n}$ present in the constitutive Eqn. (1). In particular, defining as $\beta$ the ratio between the principal strains $\left(\varepsilon_{\max }\right.$ and $\left.\varepsilon_{\min }\right)$ measured in the sheet plane:

$$
\beta=\frac{\varepsilon_{\min }}{\varepsilon_{\max }}
$$

the formability limit parameter was determined through the following ratio:

$$
F L P=\frac{\varepsilon_{\max }}{F L C\left(\varepsilon_{\min }\right)}
$$

where by FLC $\left(\varepsilon_{\min }\right)$ an analytical description of the formability limit curve as a function of the principal strain $\varepsilon_{\text {min }}$ is intended. In the case where $\beta \leq 0$ it can be obtained:

$$
\operatorname{FLC}\left(\varepsilon_{\text {min }}\right)=\frac{n}{1+\beta}
$$

while for $\beta>0$ :

$$
\operatorname{FLC}\left(\varepsilon_{\min }\right)=2 n \frac{1+\beta+\beta^{2}}{(1+\beta)\left(2=\beta+2 \beta^{2}\right)}
$$

Fig. 9 represents the FLC curve for the material under examination.

The use of the FLP parameter allows monitoring, during a plastic deformation process, the position and the moment in which the instability condition occurs (FLP = 1).

\section{NUMERICAL-EXPERIMENTAL COMPARISON}

$\mathrm{T}$ he finite element analysis allows to represent the FLP parameter distribution in the sheet as well as to define the trend of the force-displacement curve of the punch. Fig. 10 shows the reaching of the instability condition (FLP $=$ 1) at the pole of the sheet, both in the case of three-dimensional and two-dimensional modeling, in perfect lubrication conditions $(\mu=0)$. It should be noted that the simulation results are independent of the considered element type. Moreover, from Fig. 11 it is possible to compare the FEM results regarding the force-displacement curve of the punch in the case of $\mu=0$. 


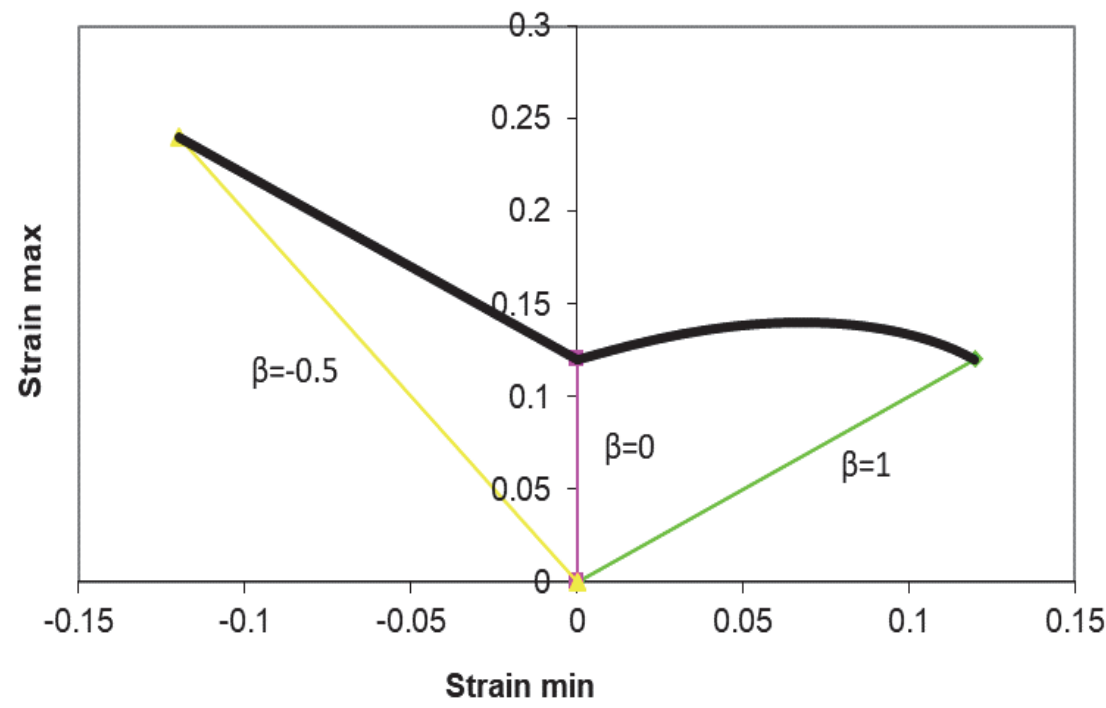

Figure 9: AA6060 alloy forming limit curve.

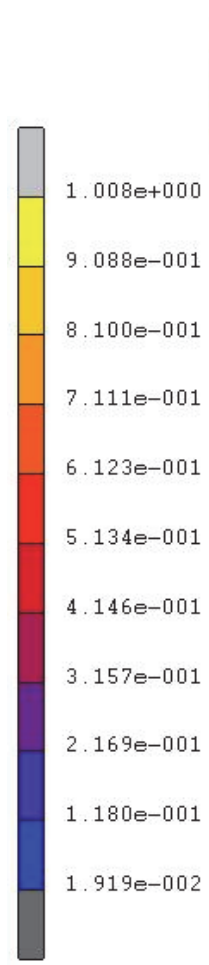

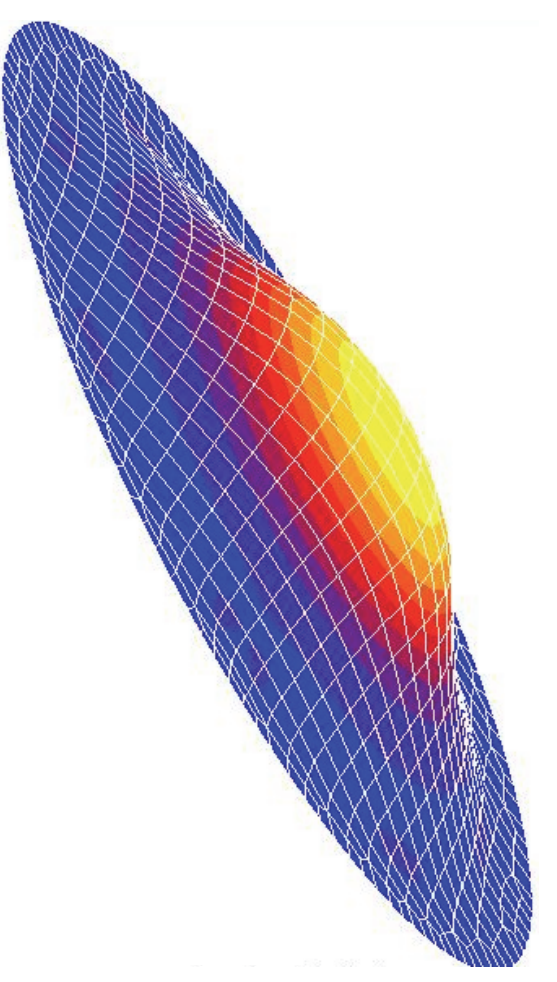

(a)

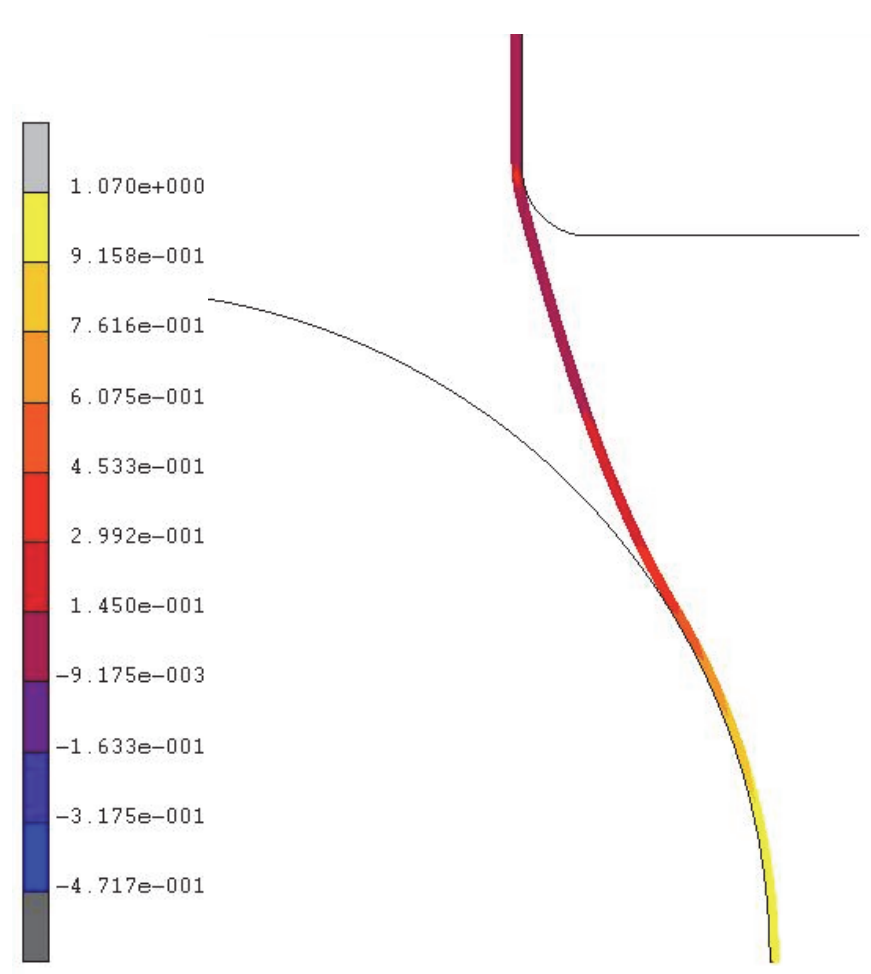

(b)

Figure 10: Instability condition (FLP $=1$ ) at the sheet pole: (a) using shell elements, (b) using axisymmetric elements.

The experimental activity was conducted under three different lubrication conditions:

- No lubrication;

- Use of a sheet of polytetrafluoroethylene (PTFE), better known with the trade name Teflon ${ }^{\circledR}$;

- Use of grease containing graphite.

The results in terms of the force-stroke curve of the punch are shown in Fig. 12. From Fig. 12, it can be seen that the fracture was determined after a stroke of about $28 \mathrm{~mm}$ in the case without lubrication. The displacement measured at the fracture point increases and reaches values of about $32 \mathrm{~mm}$ and $36 \mathrm{~mm}$ using graphite grease and PTFE as a lubricant, 
respectively. In Fig. 13, the force-displacement curves of the punch, obtained by means of 2D finite element analysis for a coefficient of friction of $0.05,0.1$ and 0.2 , is presented until the instability condition (FLP=1) occurs. Figs. 12 and 13 show that the stroke tended to increase under conditions both of instability (FEM) and fracture (experimental) by improving the lubrication conditions.

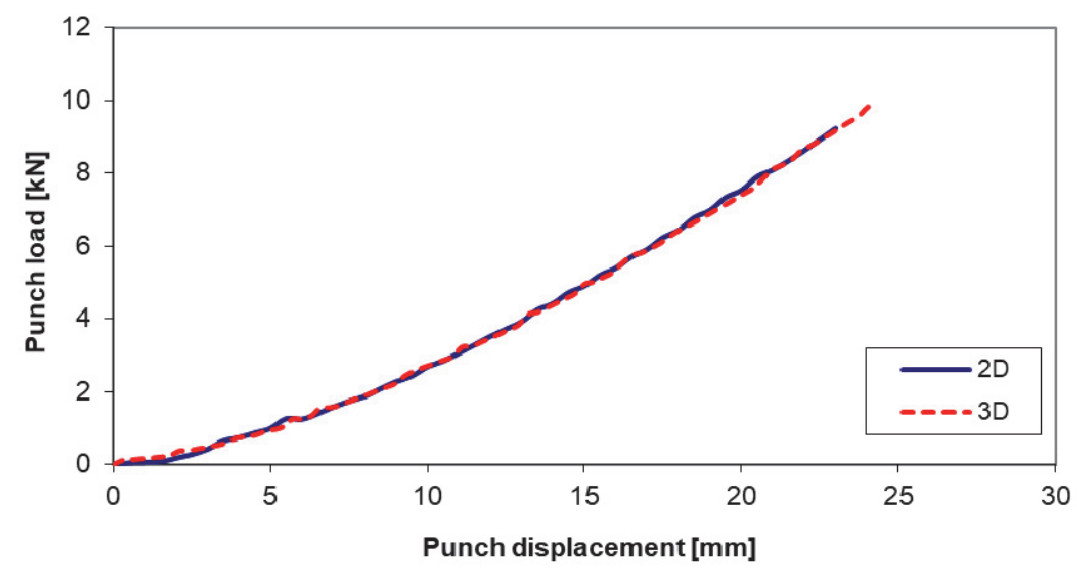

Figure 11: Comparison between the force-stroke curves of the punch, obtained by FEM for FLP = 1, under perfect lubrication conditions, using both shell (3D) and axisymmetric elements (2D).

The described comparison makes it possible to validate, in the practice of designing a plastic deformation process, the use of the criterion, introduced in the 3D and 2D FEM code, which establishes the occurrence of instability conditions in the sheet to be deformed.

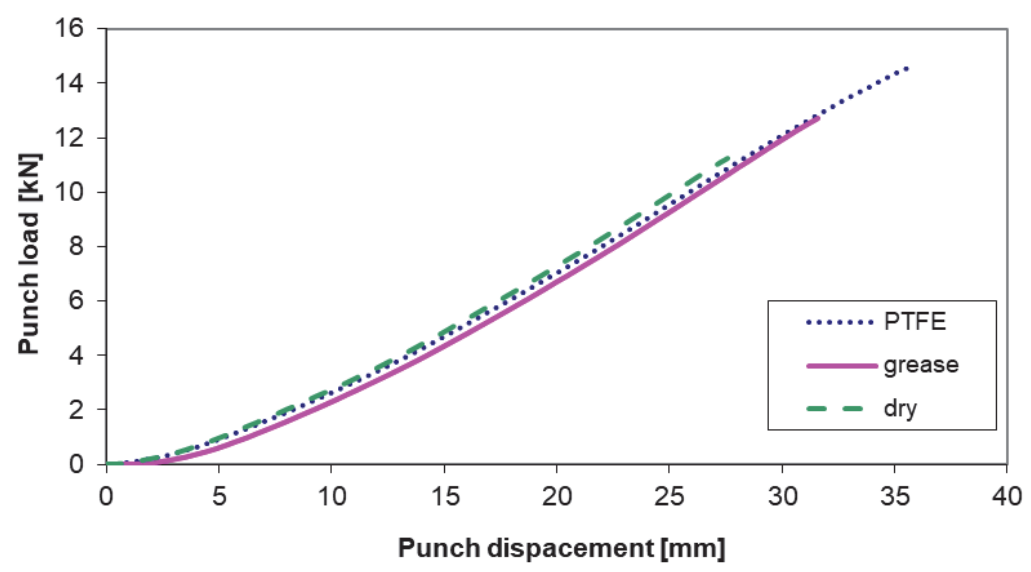

Figure 12: Comparison between the force-displacement curves of the punch, obtained experimentally for different friction conditions until the sheet fracture occurring.

\section{Conclusions}

he aim of the work was the development of a calculation model useful for checking the feasibility of forming sheet metal components, using the formability limit curve. The behavior of the AA6060 alloy was evaluated in terms of mechanical strength, with the description of the flow stress curve and the FLC. The model was based on the finite element simulation of the sheet metal forming process using the commercial software MSC.Marc. In a first phase, the results from the 3D and 2D FEM modeling were compared. Subsequently, the 2D model was used, under different friction conditions, to verify the feasibility of a simple axisymmetric vessel. 


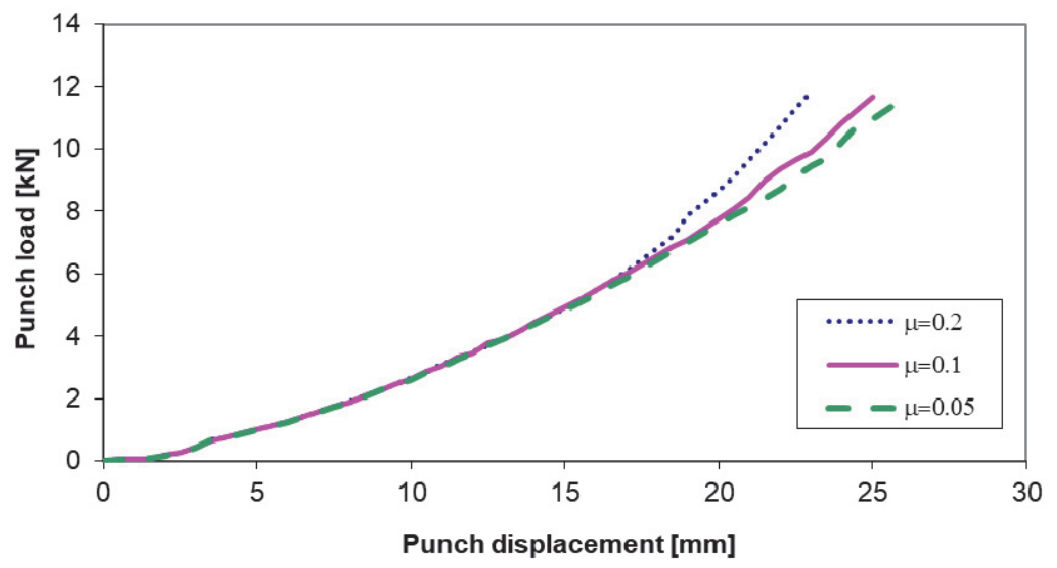

Figure 13: Comparison between the force-stroke curves of the punch, obtained by FEM-2D, under different friction conditions, until the sheet instability occurring

\section{REFERENCES}

[1] Hu, Q., Zhang, F., Li, X. and Chen, J. (2018). Overview on the Prediction Models for Sheet Metal Forming Failure: Necking and Ductile Fracture, Acta Mech. Solida Sin., 31 (3), pp. 259-289. DOI:10.1007/s10338-018-0026-6.

[2] Bouktir, Y., Chalal, H. and Abed-Meraim, F. (2018). Prediction of necking in thin sheet metals using an elasticplastic model coupled with ductile damage and bifurcation criteria, Int. J. Damage. Mech., 27(6), pp. 801-839. DOI: $10.1177 / 1056789517704030$.

[3] Bellini, C., Giuliano, G. and Sorrentino, L. (2015). Free bulging at constant pressure of superplastic sheet metal, Int. J. Eng. Techn., 7(4), pp. 1173-1178.

[4] Banabic, D., Lazarescu, L., Paraianu, L., Ciobanu, I., Nicodim, I. and Comsa, D. (2013). Development of a new procedure for the experimental determination of the forming limit curves, CIRP Ann.-Manuf. Techn., 62(1), pp. 255-258, 2013. DOI: $10.1016 /$ j.cirp.2013.03.051

[5] Swift, H.W. (1952). Plastic instability under plane stress, J. Mech. Phys. Solids, 1(1), pp. 1-18. DOI: 10.1016/0022-5096(52)90002-1.

[6] Hill, R. (1952). On discontinuous plastic states with special reference to localized necking in thin sheets, J. Mech. Phys. Solids, 1(1), pp. 19-30. DOI: 10.1016/0022-5096(52)90003-3

[7] Marciniak, Z. (1965). Stability of plastic shells under tension with kinematic boundary condition, Arch. Mech., 17, pp. $577-592$.

[8] Situ, Q., Jain, M. and Metzger, D. (2011). Determination of forming limit diagrams of sheet materials with a hybrid experimental-numerical approach, Int. J. Mech. Sci., 53(4), pp. 707-719. DOI: 10.1016/j.ijmecsci.2011.06.003.

[9] Banabic, D. (2010). Sheet Metal Forming Processes Constitutive Modelling and Numerical Simulation, Berlin, Springer. DOI: 10.1007/978-3-540-88113-1.

[10] Giuliano, G. (2012). Influence of the Metal Sheet Parameters on the Results of the Erichsen Test, Appl. Mech. Mater., 217-219, pp. 2444-2447. DOI: 10.4028/www.scientific.net/AMM.217-219.2444.

[11] Giuliano, G. (2015). Evaluation of the Coulomb Friction Coefficient in DC05 Sheet Metal Forming, Stroj. Vestn.-J. Mech. E., 61(12), pp. 709-713. DOI: 10.5545/sv-jme.2015.2733. 